\title{
Niclosamide suppresses the expansion of follicular helper T cells and alleviates disease severity in two murine models of lupus via STAT3
}

\author{
Se Gwang Jang ${ }^{1}$, Jaeseon Lee ${ }^{1}$, Seung-Min Hong ${ }^{1}$, Young-Seok Song ${ }^{1}$, Min Jun Kim¹, Seung-Ki Kwok ${ }^{1,2}$, \\ Mi-La Cho ${ }^{1}$ and Sung-Hwan Park ${ }^{1,2^{*}}$
}

\begin{abstract}
Background: Autoantibody production against endogenous cellular components is pathogenic feature of systemic lupus erythematosus (SLE). Follicular helper $T\left(T_{F H}\right)$ cells aid in B cell differentiation into autoantibody-producing plasma cells (PCS). The IL-6 and IL-21 cytokine-mediated STAT3 signaling are crucial for the differentiation to $T_{F H}$ cells. Niclosamide is an anti-helminthic drug used to treat parasitic infections but also exhibits a therapeutic effect on autoimmune diseases due to its potential immune regulatory effects. In this study, we examined whether niclosamide treatment could relieve lupus-like autoimmunity by modulating the differentiation of $\mathrm{T}_{\mathrm{FH}}$ cells in two murine models of lupus.

Methods: 10 -week-old MRL//pr mice were orally administered with $100 \mathrm{mg} / \mathrm{kg}$ of niclosamide or with $0.5 \%$ methylcellulose (MC, vehicle) daily for 7 weeks. TLR7 agonist, resiquimod was topically applied to an ear of 8-week-old C57BL/6 mice 3 times a week for 5 weeks. And they were orally administered with $100 \mathrm{mg} / \mathrm{kg}$ of niclosamide or with $0.5 \%$ MC daily for 5 weeks. Every mouse was analyzed for lupus nephritis, proteinuria, autoantibodies, immune complex, immune cell subsets at the time of the euthanization.

Results: Niclosamide treatment greatly improved proteinuria, anti-dsDNA antibody levels, immunoglobulin subclass titers, histology of lupus nephritis, and C3 deposition in MRL/Ipr and R848-induced mice. In addition, niclosamide inhibited the proportion of $\mathrm{T}_{\mathrm{FH}}$ cells and PCS in the spleens of these animals, and effectively suppressed differentiation of $\mathrm{FF}_{\mathrm{FH}}$-like cells and expression of associated genes in vitro.
\end{abstract}

Conclusions: Niclosamide exerted therapeutic effects on murine lupus models by suppressing $T_{F H}$ cells and plasma cells through STAT3 inhibition.

Keywords: Systemic lupus erythematosus, MRL/Ipr, R848-induced model, Niclosamide, STAT3, Follicular helper T cells

\footnotetext{
*Correspondence: rapark@catholic.ac.kr

${ }^{2}$ Division of Rheumatology, Department of Internal Medicine, Seoul St.

Mary's Hospital, College of Medicine, The Catholic University of Korea, Seoul, Republic of Korea

Full list of author information is available at the end of the article
}

\section{Background}

Systemic lupus erythematosus (SLE) is a chronic systemic autoimmune disease, with manifestations in multiple organ systems [1]. Damage to tissues in SLE results from the production of autoantibodies and immune complexes, mediated by the interplay between the innate and adaptive immune responses of autoreactive $\mathrm{B}$ and

(c) The Author(s) 2021. This article is licensed under a Creative Commons Attribution 4.0 International License, which permits use, sharing, adaptation, distribution and reproduction in any medium or format, as long as you give appropriate credit to the original author(s) and the source, provide a link to the Creative Commons licence, and indicate if changes were made. The images or other third party material in this article are included in the article's Creative Commons licence, unless indicated otherwise in a credit line to the material. If material is not included in the article's Creative Commons licence and your intended use is not permitted by statutory regulation or exceeds the permitted use, you will need to obtain permission directly from the copyright holder. To view a copy of this licence, visit http://creativeco mmons.org/licenses/by/4.0/. The Creative Commons Public Domain Dedication waiver (http://creativecommons.org/publicdomain/ zero/1.0/) applies to the data made available in this article, unless otherwise stated in a credit line to the data. 
T lymphocytes [2, 3]. Although the exact pathogenesis of SLE has not yet been elucidated, various factors are known to be involved in driving SLE $[1,4]$.

Follicular helper $\mathrm{T}\left(\mathrm{T}_{\mathrm{FH}}\right)$ cells are a specialized subset of $\mathrm{CD}_{4}^{+} \mathrm{T}$ cells required for germinal center (GC) formation and ultimately the development of memory $\mathrm{B}$ cells and high-affinity long-lived plasma cells (PCs) [5]. $\mathrm{T}_{\mathrm{FH}}$ cells express high levels of the chemokine receptor CXCR5, which promotes the migration of $\mathrm{T}_{\mathrm{FH}}$ cells to the $\mathrm{B}$ cell follicles in response to the specific ligand CXCL13 [6]. The transcription factor B cell lymphoma 6 (Bcl-6) is a master regulator of $\mathrm{T}_{\mathrm{FH}}$ cells and is critical for $\mathrm{T}_{\mathrm{FH}}$ cell differentiation [7]. However, additional transcription factors, including interferon-regulatory factor 4 (IRF4), basic leucine zipper transcriptional factor ATF-like (BATF), and Maf bZIP transcription factor (MAF), also play an important role in $\mathrm{T}_{\mathrm{FH}}$ cell differentiation [8]. B lymphocyte-induced maturation protein 1 (Blimp-1) has been found to be the most downregulated transcription factor in $\mathrm{T}_{\mathrm{FH}}$ cells, and acts as a suppressor of $\mathrm{T}_{\mathrm{FH}}$ cell differentiation $[9,10]$. Circulating $\mathrm{T}_{\mathrm{FH}}$ cells are significantly increased in the blood of SLE patients and correlate with disease severity. In addition, $\mathrm{T}_{\mathrm{FH}}$ cells are expanded in lupus-prone mice and lead to an increase in IL-21 production $[4,11]$.

Signal transducer and activator of transcription 3 (STAT3) plays a key role in regulating inflammation and innate/adaptive immune responses [12]. STAT3 promotes $\mathrm{T}_{\mathrm{FH}}$ cell differentiation by positively regulating the transcription factors Bcl- 6 and T cell factor 1 (TCF-1) $[13,14]$. STAT3 signaling is enhanced by IL- 6 and IL-21, which promotes the expression of Bcl-6. Previous studies have demonstrated that STAT3 is involved in the pathogenesis of SLE; indeed, a STAT3 genetic deficiency, STAT3 inhibitors, and agents that inhibit expression of STAT3 all provide a protective effect against SLE [15-18].

Several classes of agents, such as non-steroidal antiinflammatory drugs (NSAIDs), immunosuppressants, and corticosteroids are used to treat lupus. However, these agents have a wide range of serious side effects, so their use is limited [1]. Accordingly, now, many studies are ongoing to reduce the failure of therapy by developing new agents having maximum efficacy with minimum side effects. Niclosamide is an FDA-approved anti-helminthic drug and has wide safety and few side effects, so it can be safely used for long-term period in the treatment of chronic diseases [19]. Furthermore, it is multifunctional and has also been reported by several groups to play a potential role in the treatment of various solid tumors $[20,21]$. In addition, it may also be effective against autoimmune diseases and renal fibrosis due to its potential anti-inflammatory effects $[22,23]$. Niclosamide is a potent inhibitor of STAT3 signaling [24]. However, the effect of niclosamide on $\mathrm{T}_{\mathrm{FH}}$ cells in lupus-prone mice has not yet been investigated.

In this study, we examined whether in vivo treatment with niclosamide had a therapeutic effect in lupus-prone $\mathrm{MRL} / \mathrm{lpr}$ and R848-induced mice by examining proportion of $\mathrm{T}_{\mathrm{FH}}$ cells and PCs in the spleen and peripheral blood (PB). We additionally investigated the impact of niclosamide on $\mathrm{T}_{\mathrm{FH}}$-like cells in vitro. The $\mathrm{T}_{\mathrm{FH}}$ cells were sensitive to inhibition of STAT3 signaling both in vitro and in vivo. STAT3 signaling inhibition resulted in decreased numbers of $\mathrm{T}_{\mathrm{FH}}$ cells in the spleen, which was correlated with an improvement in the lupus manifestation. Our findings demonstrate that niclosamide is a critical regulator of $\mathrm{T}_{\mathrm{FH}}$ cells, which are a therapeutic target for SLE.

\section{Materials and methods \\ Animals}

MRL/lpr mice were purchased from SLC Inc. (Japan). C57BL/6 mice were purchased from OrientBio (Korea). Niclosamide (Sigma-Aldrich, St Louis, MO, USA) was resuspended in $0.5 \%$ methyl cellulose (Sigma-Aldrich, St Louis, MO, USA) for in vivo studies or in 5\% DMSO for in vitro use. Female 10-week-old MRL/lpr mice received daily administration of vehicle $(\mathrm{n}=7)$ or niclosamide $(\mathrm{n}=7 ; 100 \mathrm{mg} / \mathrm{kg})$ for 7 weeks by oral gavage. All mice were sacrificed at 16 weeks of age. Female 8-week-old C57BL/6 mice were treated via epicutaneous application of $50 \mu \mathrm{g}$ of the TLR7 agonist resiquimod (R848; SigmaAldrich) dissolved in $10 \mu \mathrm{l}$ of acetone, with or without $100 \mathrm{mg} / \mathrm{kg}$ of niclosamide daily for 4 weeks, or acetone alone as a control, to the right ear three times a week until euthanasia. All procedure of animal research were provided in accordance with the Laboratory Animals Welfare Act, the Guide for the Care and Use of Laboratory Animals and the Guidelines and Policies for Rodent experiment provided by the IACUC(Institutional Animal Care and Use Committee) in school of medicine, The Catholic University of Korea. (Approval numbers: CUMS-2018-0341-02 and 2018-0236-02).

\section{Enzyme-linked immunosorbent assay (ELISA)}

Cytokines in sera or spleen lysates were assayed using mouse IL- 6 and IL-21 Duoset ELISA kits (R\&D systems, Minneapolis, MN, USA) according to the manufacturer's instructions. The serum levels of anti-double-stranded DNA (dsDNA) IgG antibodies were measured by ELISA following the manufacturer's instructions (Alpha Diagnostics, San Antonio, TX, USA). Total IgG, IgG1, IgG2a, and IgM levels in the sera of the mice were measured by ELISA following the manufacturer's instructions (Bethyl Laboratories, Montgomery, TX, USA). 


\section{Measurement of urine albumin to creatinine ratio}

Urine albumin and creatinine concentrations were measured using a mouse albumin ELISA assay (Bethyl Laboratories) and a creatinine assay ( $R \& D$ systems), respectively, according to the manufacturer's directions. Urine albumin excretion was expressed as the ratio of urine albumin to creatinine (ACR).

\section{Histological assessment of the kidney}

Kidney tissues were fixed with formalin and embedded in paraffin, cut into $3 \mu \mathrm{m}$ sections, and stained with periodic acid-Schiff (PAS) stain. Kidney histological pathology was evaluated using the lupus nephritis classification system, as described [25].

\section{Immunofluorescence}

Kidney tissues were stained with anti-C3 (Abcam, Cambridge, UK) at $4{ }^{\circ} \mathrm{C}$ overnight, followed by $2 \mathrm{~h}$ incubation with secondary antibodies conjugated to Alexa488. Nuclei were stained with 4',6-diamidino-2-phenylindole (DAPI; Invitrogen, Carlsbad, CA, USA). Isotype control staining was conducted via probing with rat/rabbit/ mouse IgG, rather than primary antibodies. Confocal images were acquired using an LSM 800 confocal microscope (Zeiss, Oberkochen, Germany).

\section{Flow cytometry}

Spleens were minced in RPMI 1640 medium and filtered through a $40-\mu \mathrm{m}$ cell strainer to prepare single-cell suspensions. For intracellular staining, cells were stimulated with $25 \mathrm{ng} / \mathrm{mL}$ phorbol 12-myristate 13-acetate (PMA, Sigma-Aldrich) and $250 \mathrm{ng} / \mathrm{mL}$ ionomycin (SigmaAldrich) with monensin-containing GolgiStop (BD biosciences, San Jose, CA, USA) for 5 h. Cells were harvested and stained with surface eFluor780-fixable viability dye (FVD) (eBioscience, Carlsbad, CA, USA), Pacific Blue-anti-CD90.2 (Biolegend, San Diego, CA, USA), PerCP-Cy5.5-anti-CD4 (Biolegend), FITC-anti-CXCR5 (Biolegend), Brilliant Violet 605-anti-PD-1 (Biolegend), APC-anti-CD19 (Biolegend), PE-anti-CD138 (BD Biosciences), and Alexa Fluor A488-anti-GL7 (eBioscience) antibodies. Blood samples were collected from the retroorbital sinus. Red blood cell were lysed with an ammonium-chloride-potassium lysis buffer, then stained with surface eFluor 780-Fixable viability dye (eBioscience), Pacific Blue-anti-CD90.2, PerCP-Cy5.5-anti-CD4, and PE-anti-CD8 antibodies. Flow cytometric analysis was performed on a LSRII Fortessa (BD biosciences), and the data were analyzed using FlowJo software (Tree Star, Ashland, OR, USA).

\section{Western blot}

Total protein was extracted using RIPA buffer containing Halt protease/phosphatase inhibitor cocktail (Thermo Fisher Scientific, Rockford, IL, USA). For immunoblotting, $30 \mu \mathrm{g}$ of protein was separated using $10 \%$ sodium dodecyl sulfate polyacrylamide gel electrophoresis (SDSPAGE), then transferred onto polyvinylidene fluoride membrane (Bio-Rad, Hercules, CA, USA), and probed with the following antibodies: anti-p-STAT3 ${ }_{\mathrm{Y} 705}$, antiSTAT3, anti-Bcl-6, anti-TCF-1 (Cell signaling technology, Danvers, MA, USA), and anti- $\beta$-actin (Sigma-Aldrich). Subsequently, the membranes were incubated with horseradish peroxidase-conjugated goat anti-rabbit IgG or goat anti-mouse IgG (Thermo Fisher Scientific). Reactive proteins on the membrane were visualized using SuperSignal $^{\circledR}$ West Pico Chemiluminescent substrate (Thermo Fisher Scientific), and the membrane was then exposed on an Amersham Imager 600 (GE healthcare, Healthcare, Chicago, IL, USA).

\section{Real-time PCR}

Total RNA was collected using an RNA iso plus reagent (Takara, Kusatsu, Japan). Up to $1 \sim 2 \mu \mathrm{g}$ of total RNA was converted to complementary DNA using a Transcriptor First-Strand cDNA Synthesis kit (Roche Diagnostics, Penzberg, Germany). A LightCycler 96 instrument (Roche) was used for PCR amplification and analysis. All reactions were performed with SYBR Green I Master Mix, according to the manufacturer's instructions. Primers were designed using the web tool from GenScript ${ }^{\circledR}$ (http://www.genscript.com). Sequences are as follows (forward and reverse, respectively): beta actin, 5'-GGA CTTCGAGCAAGAGATGG-3 ${ }^{\prime}$ and $5^{\prime}$-TGTGTTGGG GTACAGGTCTTT-3'; Bcl-6, 5'-GCCGGCTCAATA ATCTCGTGAACA- $3^{\prime}$ and $5^{\prime}$-CCAGCAGTATGGAGG CACATCT-3'; CXCR5, 5'-ACTCCTTACCACAGTGCA CC-3' and 5'-GGAAACGGGAGGTGAACCA-3'; and Blimp-1, 5'-ATGGAGGACGCTGATATGAC-3' and 5'-CCTTACTTACCACGCCAATAAC- $3^{\prime}$. All mRNA expression levels were normalized to beta actin expression. Relative fold induction was calculated, following the equation $2^{-(\Delta \mathrm{Cq})}$ or $2^{-(\Delta \Delta \mathrm{Cq})}$, where $\Delta \Delta \mathrm{Cq}$ is $\Delta \mathrm{Cq}_{(\text {target })}$ $\Delta \mathrm{Cq}_{\text {(beta actin) }}, \Delta \mathrm{Cq}$ is $\mathrm{Cq}_{\text {(stimulated) }}-\mathrm{Cq}_{\text {(unstimulated) }}$, and $\mathrm{Cq}$ is the cycle at which the threshold is crossed. PCR product quality was monitored using post-PCR melting curve analysis.

\section{$\mathrm{T}_{\mathrm{FH}}$-like cell differentiation}

CD4 ${ }^{+} \mathrm{T}$ cells were purified from spleens of MRL/lpr and C57BL/6 mice using the CD4 ${ }^{+} \mathrm{T}$ cell Isolation Kit (Miltenyi Biotec, Bisley, UK) according to the manufacturer's instructions. For $\mathrm{T}_{\mathrm{FH}}$-like cell differentiation, purified 
$\mathrm{CD}^{+} \mathrm{T}$ cells were seeded at $1 \times 10^{6}$ cells/well and were activated with mouse T-activator CD3/CD28 Dyna-

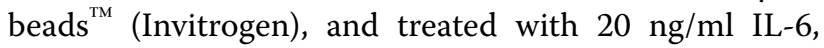
$20 \mathrm{ng} / \mathrm{ml} \mathrm{IL-21,} 10 \mu \mathrm{g} / \mathrm{ml}$ anti-IL-4, $10 \mu \mathrm{g} / \mathrm{ml}$ anti-IFN- $\gamma$, and $20 \mu \mathrm{g} / \mathrm{ml}$ anti-TGF- $\beta$ (R\&D Systems) for 4 days with or without niclosamide.

\section{Co-culture of mouse $B$ cells and $\mathrm{T}_{\mathrm{FH}^{-}}$-like cells}

$\mathrm{T}_{\mathrm{FH}}$-like cells from spleens of C57BL/6 mice were first cultured for 4 days with or without niclosamide. B cells were purified from spleens of C57BL/6 mice using a B cell Isolation kit (Miltenyi Biotec) according to the manufacturer's instructions. CD19 $9^{+}$B cells were co-cultured with $\mathrm{T}_{\mathrm{FH}}$-like cells $\left(1 \times 10^{6}\right.$ cells/well, 1:1 ratio $)$ and were stimulated with $50 \mathrm{ng} / \mathrm{ml}$ IL-4 (PeproTech, Rocky Hill, NJ, USA), $5 \mu \mathrm{g} / \mathrm{ml}$ anti-IgM (Jackson ImmunoResearch, West Grove, PA, USA), and $5 \mu \mathrm{g} / \mathrm{ml}$ anti-CD40 (eBioscience) in Roswell Park Memorial Institute (RPMI)-1640 medium (Gibco, Carlsbad, CA, USA) with 10\% FBS for 3 days. IgG were measured using an ELISA kit (Bethyl Laboratories).

\section{Statistics analysis}

Statistical analyses were performed in GraphPad Prism version 7.0 software (GraphPad, San Diego, CA, USA). Statistical significance was determined by t-tests for two groups, and by one-way ANOVA with Tukey's multiple comparisons tests for three or more groups. $\mathrm{P}<0.05$ was considered statistically significant.

\section{Results}

Effects of niclosamide on lupus nephritis in MRL/Ipr mice To assess whether niclosamide ameliorates clinical features of LN, we orally administered 10-week-old MRL/lpr mice with niclosamide or vehicle daily for 7 weeks. While the kidney weights increased with disease progression in this spontaneous lupus model, niclosamide treatment inhibited kidney enlargement (Fig. 1a). Proteinuria, one of the major measures of LN, was reduced upon niclosamide treatment, in contrast to the vehicle (Fig. 1b). We next measured autoantibodies in these mice, which is the hallmark of SLE. Niclosamide treatment decreased serum levels of anti-dsDNA IgG (Fig. 1c), in addition to the serum levels of IgG, IgG1, and IgM (Fig. 1d). IL-6 and IL-21 are pro-inflammatory cytokine for lupus progression, and also important regulators of $\mathrm{T}_{\mathrm{FH}}$ cell generation. We found that niclosamide treatment significantly decreased the serum levels of IL-6 and IL-21 (Fig. 1e).

Furthermore, MRL/lpr mice developed severe renal injury, which was characterized by diffuse glomerular, perivascular, and interstitial mononuclear cell infiltration, tubular cast deposition, increased mesangial matrix, and immune complex deposition. Niclosamide ameliorated these renal pathological features, as judged by changes in the histological scores and C3 immune complex deposition (Fig. 1f, g). These data suggest that niclosamide treatment significantly prevented LN in MRL/lpr mice.

\section{Niclosamide inhibits CD90.2 $2^{+} \mathrm{T}$ cell, DNT cell, $\mathrm{T}_{\mathrm{FH}}$ cell and $\mathrm{PC}$ differentiation in MRL/lpr mice}

To investigate the cell types related to the decreased disease severity by niclosamide in MRL/lpr mice, we analyzed the proportion of $\mathrm{T}$ cell and $\mathrm{B}$ cell subsets in spleens and $\mathrm{PB} . \mathrm{CD} 90.2^{+} \mathrm{CD} 4^{-} \mathrm{CD} 8^{-}$double-negative $\mathrm{T}$ cells (DNT cells) are expanded in SLE patients, as well as massive splenomegaly and lymphadenopathy caused by hyperproliferation of DNT cells in MRL/lpr mice [26]. $\mathrm{T}_{\mathrm{FH}}$ cells, defined as $\mathrm{CD} 4^{+} \mathrm{CXCR}^{+}{ }^{+} \mathrm{PD}-1^{+}$, play a crucial role in GC formation and the production of antigen-specific memory B cells and PCs, thereby contributing to SLE disease progression $[4,27]$. We analyzed the proportion of CD90.2 $2^{+} \mathrm{T}$ cells, DNT cells, $\mathrm{T}_{\mathrm{FH}}$ cells and PCs in the spleens and PB of MRL/lpr mice. Niclosamide treatment had a significantly lower proportion of spleen CD90.2 $2^{+} \mathrm{T}$ cells than the vehicle treatments. The proportion of $\mathrm{PB} C D 90.2^{+} \mathrm{T}$ cells was significantly decreased in the niclosamide treatment compared with the vehicle treatment (Fig. 2a, b). Likewise, the spleen DNT cells proportion was decreased by niclosamide treatment (Fig. 2c, d). We found that the proportion of $\mathrm{T}_{\mathrm{FH}}$ cells in both samples from these mice were significantly decreased by niclosamide treatment (Fig. 2e, f). In addition, The proportion of Th1, Th17, and regulatory $T$ (Treg) cells were analyzed in spleen samples using flow cytometry. The alteration of the spleen Th1 and Th17 cells proportion was not significant (Additional file 1: Figure S1a-c). However, Treg cells, characterized by immunomodulatory capabilities, were significantly increased by niclosamide treatment (Additional file 1: Figure S1d and e). The Treg/ Th17 ratio was significantly increased in the niclosamide group compared with the vehicle group in spleen (Additional file 1: Figure S1f). In addition to, the proportion of PCs in both samples from these mice were significantly reduced by niclosamide treatment (Fig. 2g, h). These data indicate that niclosamide could suppress the number of CD $90.2^{+}$cells, DNT cells, $\mathrm{T}_{\mathrm{FH}}$ cells and PCs in the spleens and $\mathrm{PB}$ of MRL/lpr mice.

\section{Niclosamide regulates major transcription factors involved in $\mathrm{T}_{\mathrm{FH}}$ cell differentiation}

We next analyzed the activity of the STAT3/Bcl-6/ TCF-1 pathways in the spleens of each animal group to elucidate the molecular mechanisms regulating the effects of niclosamide treatment. Western blot analysis revealed that expression of p-STAT3/Bcl-6/TCF-1 was significantly decreased in the splenocytes of 

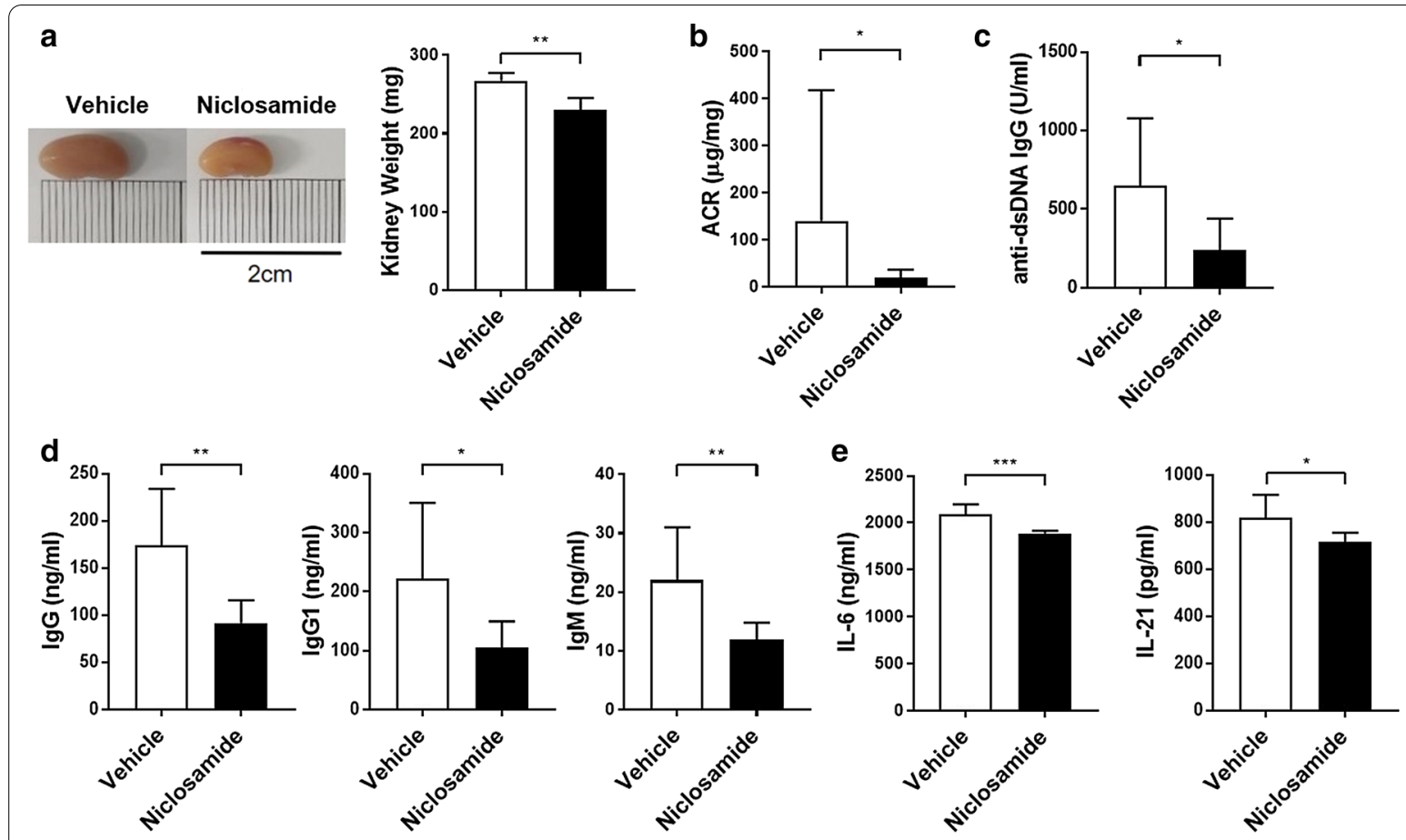

$\mathbf{f}$

\section{Vehicle Niclosamide}
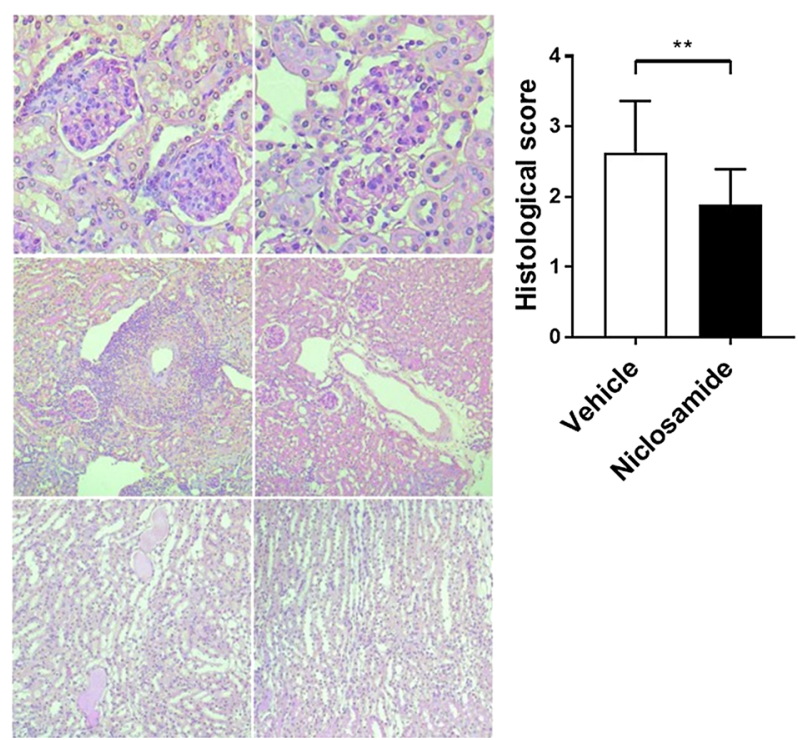

g Vehicle

Niclosamide
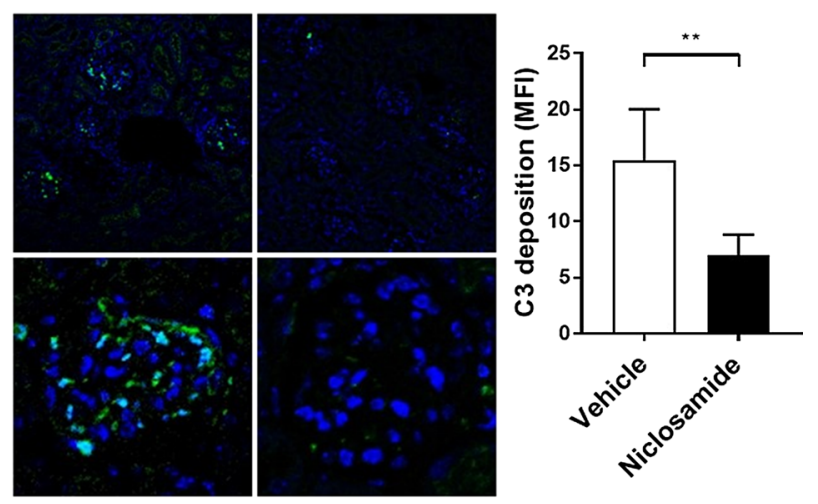

Fig. 1 Niclosamide ameliorates disease aggravation in MRL//pr mice. Female 10-week-old MRL//pr mice were orally administered 0.5\% methyl cellulose (vehicle, $n=7$ ), or $100 \mathrm{mg} / \mathrm{kg}$ niclosamide (Niclosamide, $n=7$ ) daily until they were 16-week-old. a Left, Representative photographs documenting the enlargement of kidneys. Right, kidney weights in vehicle, niclosamide groups. b Urine albumin levels normalized to creatinine. c Serum levels of anti-dsDNA IgG antibody. d Serum levels of antibody subclasses (IgG, IgG1, and lgM). e Serum levels of IL-6 and IL-21. $\mathbf{f}$ Left, representative photomicrographs of PAS-stained sections of kidney. Original magnification $\times 200$ (upper), $\times 100$ (middle, bottom). Right, histological score. $\mathbf{g}$ Left, representative immunofluorescent images of kidney C3 staining. Original magnification $\times 100$ (upper), $\times 400$ (bottom). Right, MFI of C3 deposition. Data shown as mean \pm SD. t-test was performed. ${ }^{*} P<0.05,{ }^{* *} P<0.01,{ }^{* * *} P<0.001$

niclosamide-treated mice as compared to vehicle-treated mice (Fig. 3a). Previous studies have shown that Bcl-6, CXCR5, and Blimp-1 are important regulators of $\mathrm{T}_{\mathrm{FH}}$ cell differentiation $[9,28]$. Niclosamide significantly reduced Bcl-6 and CXCR5 mRNA expression, while the mRNA levels of Blimp-1, which acts as a $\mathrm{T}_{\mathrm{FH}}$ cell differentiation 

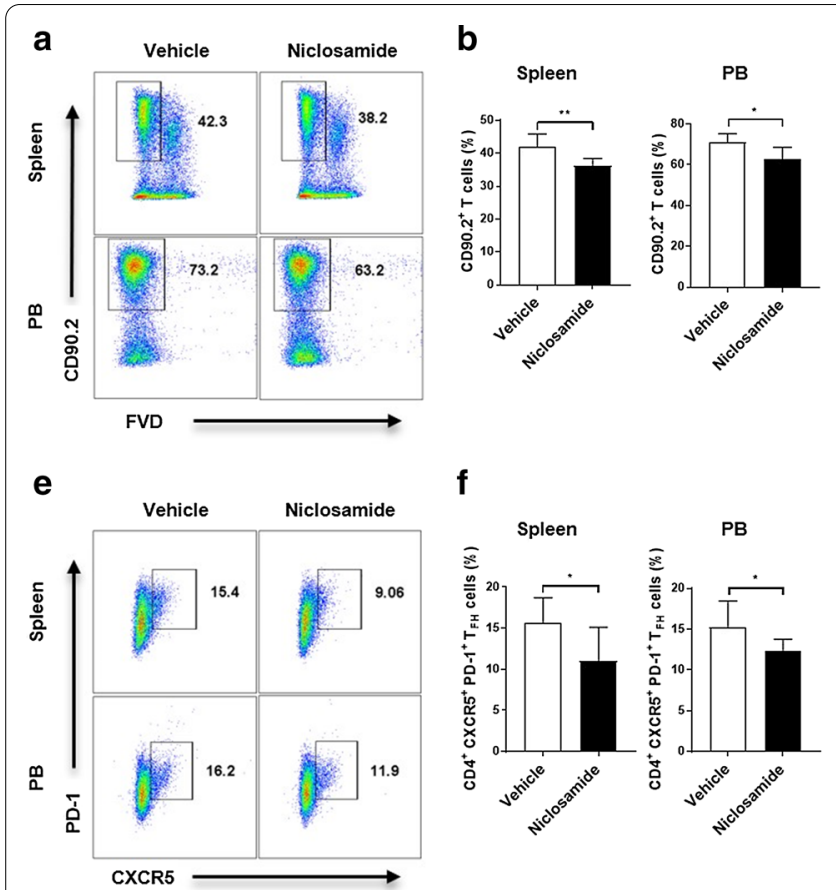

f
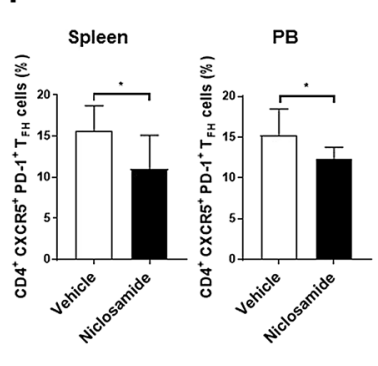
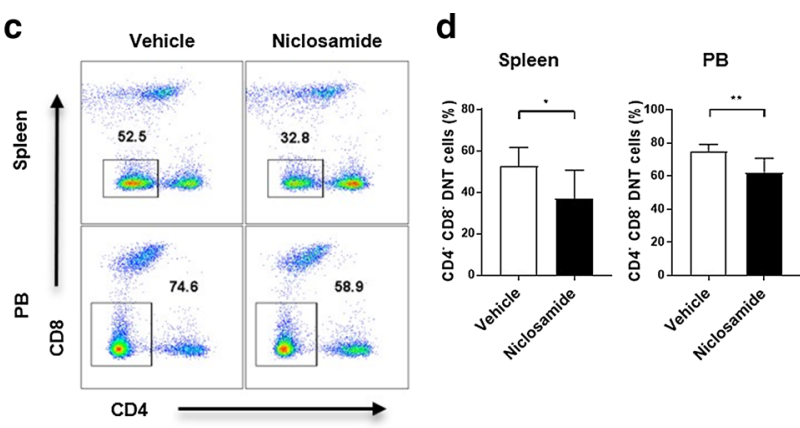

g

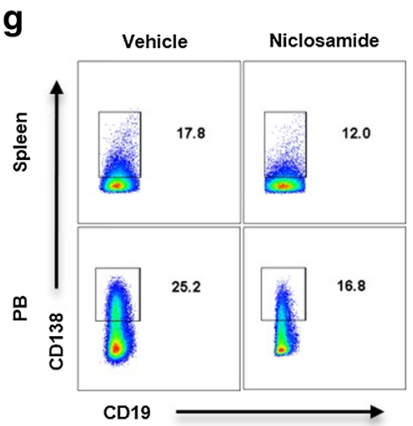

h

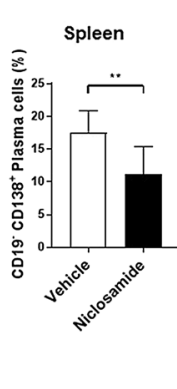

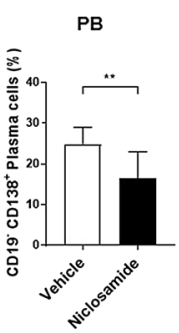

Fig. 2 Niclosamide modulates the proportion of CD $90.2^{+} T$ cells, DNT cells, $T_{F H}$ cells and PCs in the spleen and PB of MRL/lpr mice. Spleen and PB samples were collected from 16-week-old mice. a comparison of the $\mathrm{FVD}^{-}$and $\mathrm{CD} 90.2^{+}$- -cell proportion. The gating strategies were: lymphocytes as FSC-A vs SSC-A, live cells as FVD-A vs CD90.2-A b Bar graphs show mean \pm SD. c Altered proportion of DNT cells (CD4- CD8- gated on FVD$\mathrm{CD} 90.2^{+}$) by niclosamide. $\mathbf{d}$ Bar graphs show mean $\pm \mathrm{SD}$. e Data show proportion of $\mathrm{FHH}_{\mathrm{F}}$ cells $\left(\mathrm{CXCR5^{+ }} \mathrm{PD}-1^{+}\right.$gated on $\left.\mathrm{CD} 4+\right)$. $\mathbf{f}$ Bar graphs show mean \pm SD. $\mathbf{g}$ Data show proportion of PCs $\left(C D 19^{-} \mathrm{CD} 138^{+}\right.$gated on $\left.\mathrm{CD} 19^{-}\right)$. $\mathbf{h}$ Bar graphs show mean $\pm \mathrm{SD}$. t-test was performed. * $P<0.05$, ${ }^{*} P<0.01$

suppressor, was not significantly increased in spleen $\mathrm{CD}^{+} \mathrm{T}$ cells (Fig. $3 \mathrm{~b}$ ). In addition, niclosamide treatment significantly decreased the spleen levels of IL- 6 and IL-21 (Fig. 3c). Collectively, these results indicate that niclosamide is effective in regulating $\mathrm{T}_{\mathrm{FH}}$ cell-related factors.

\section{STAT3 is important for $\mathrm{T}_{\mathrm{FH}}$-like cell differentiation and $\mathrm{B}$ cell IgG production in vitro}

We further investigated the influence of niclosamide on $\mathrm{T}_{\mathrm{FH}^{-}}$-like cell differentiation in vitro, and found that niclosamide could inhibit $\mathrm{T}_{\mathrm{FH}}$-like cell differentiation (Fig. 4a). Niclosamide treatment reduced the protein levels of p-STAT3 and TCF-1 in cultured $\mathrm{T}_{\mathrm{FH}}$-like cells (Fig. 4b). In addition, niclosamide inhibited mRNA expression of Bcl-6 and CXCR5, and increased Blimp1 during the differentiation of $\mathrm{T}_{\mathrm{FH}}$-like cells (Fig. 4c). We next examined whether $\mathrm{T}_{\mathrm{FH}}$-like cells might play a pathogenic role in SLE by supporting the production of autoantibodies. When B cells were cultured with $\mathrm{T}_{\mathrm{FH}}$-like cells, IgG production was significantly increased compared to $\mathrm{CD} 4^{+} \mathrm{T}$ cells. However, when $\mathrm{B}$ cells were cultured with niclosamide-treated $\mathrm{T}_{\mathrm{FH}}$-like cells, IgG production markedly decreased (Fig. 4d). By enhancing antibody production in vitro, $\mathrm{T}_{\mathrm{FH}}$-like cells thus demonstrated their capacity to promote an antibody response. Overall, these results indicate that niclosamide not only inhibits $\mathrm{T}_{\mathrm{FH}}$-like cell differentiation, but also $\mathrm{B}$ cell IgG production.

\section{Effects of niclosamide on lupus nephritis in an R848-induced mouse model}

To further verify our findings in a different murine model, wild-type C57BL/6 mice received topical treatment on their right ears with the TLR-7 agonist R848 3 times weekly for 5 weeks. We orally administered 8-week-old R848-induced mice with niclosamide or vehicle daily for 5 weeks. R848-induced mice exhibited splenomegaly, while niclosamide treatment significantly reduced the spleen enlargement in these animals, although the cervical lymph node (cLN) size was not significantly different (Fig. $5 \mathrm{a}-\mathrm{C}$ ). The R848 group developed proteinuria compared with the control group, but the niclosamide-treated animals showed significantly diminished proteinuria compared with the R848 group (Fig. 5d). Serum levels of anti-dsDNA IgG, IgG, and IgG2a were significantly increased in the R848-induced mice as compared to the control mice. However, niclosamide treatment significantly decreased the levels of these factors (Fig. 5e, f). In 
a

Vehicle

Niclosamide

p-STAT3

STAT3

Bcl-6

TCF-1

$\beta$-actin
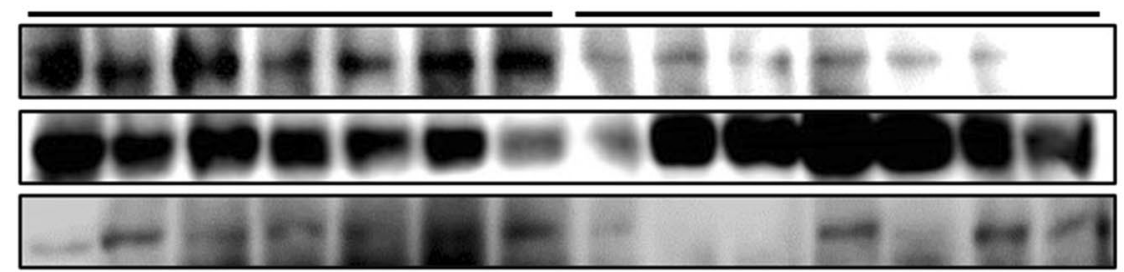

b

Bcl-6

CXCR5

Blimp-1
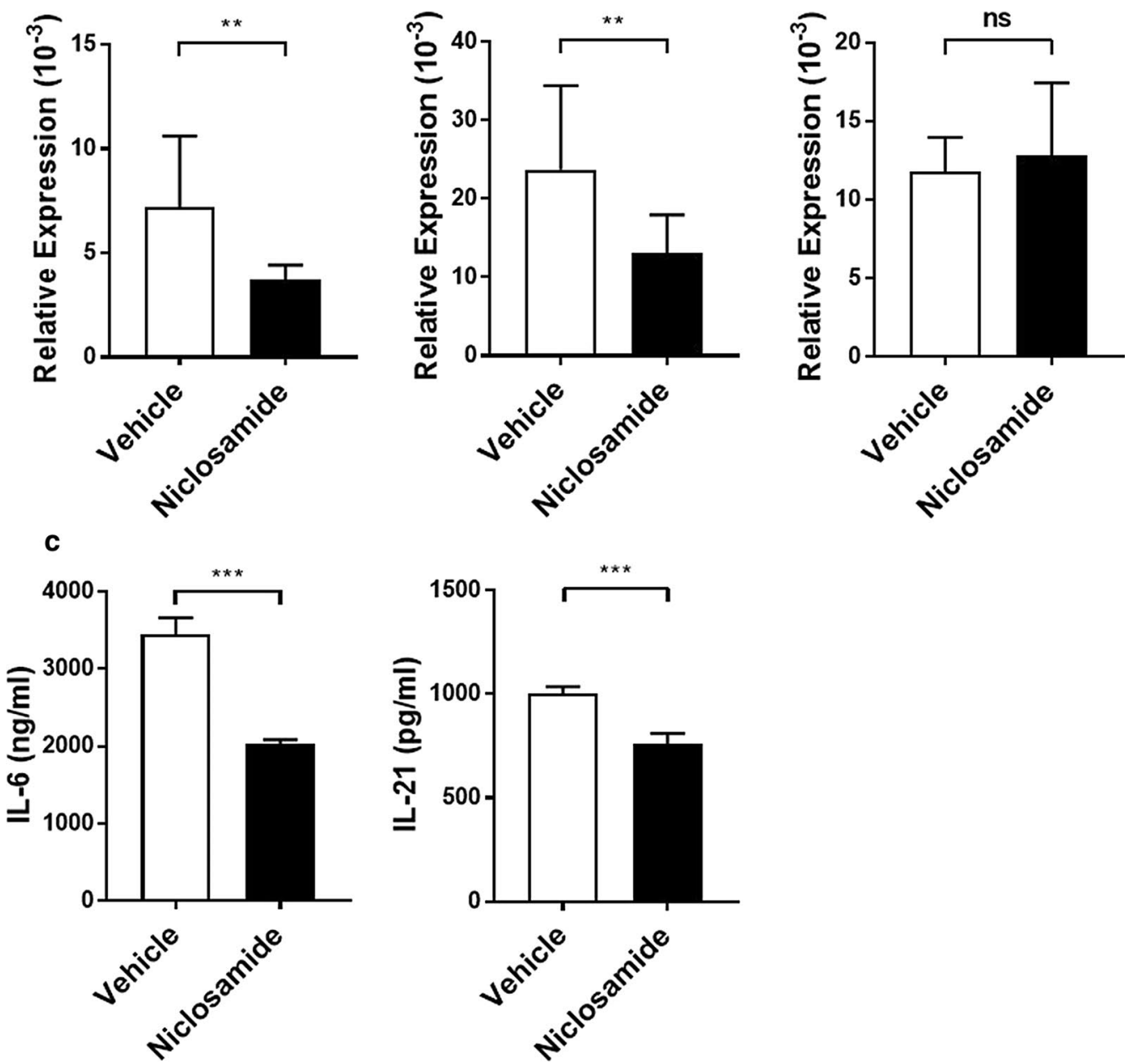

Fig. 3 Niclosamide treatment reduces $T_{F H}$-associated gene and cytokine levels in the spleens of MRL/lpr mice. a p-STAT3, BCl-6, and TCF-1 expression in the spleen were analyzed by western blot. $\mathbf{b}$ mRNA expression levels of $B C l-6, C X C R 5$, and Blimp- 1 in CD4 ${ }^{+}$T cells purified from spleens for each group of mice were measured by real-time PCR. c The levels of IL- 6 and IL-21 in the spleen homogenates were detected by ELISA. Data shown as mean $\pm \mathrm{SD}$. t-test was performed. ${ }^{* *} P<0.01,{ }^{* * *} P<0.001$, ns: not significant 

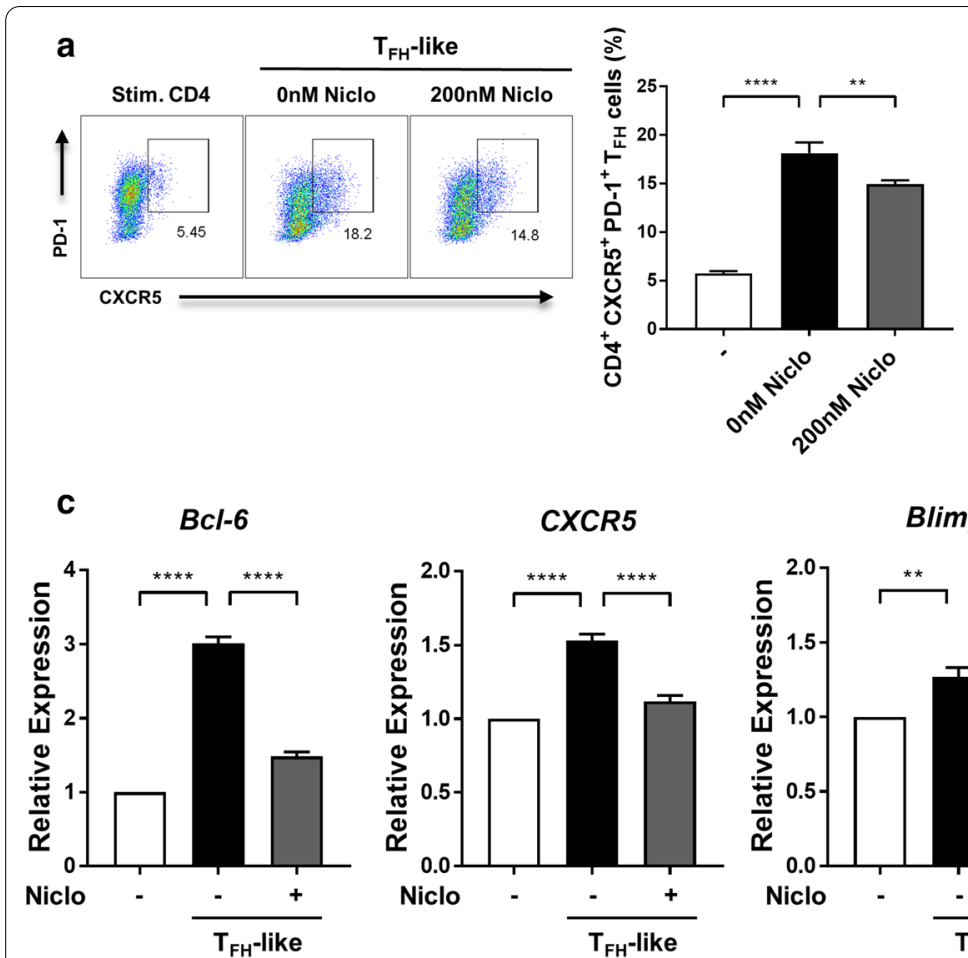
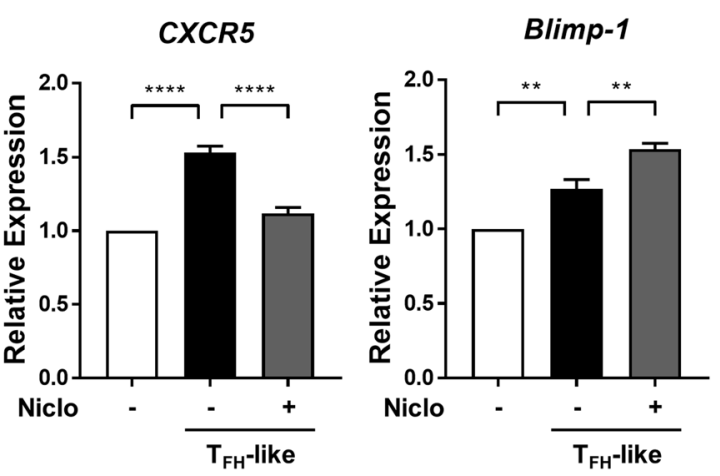

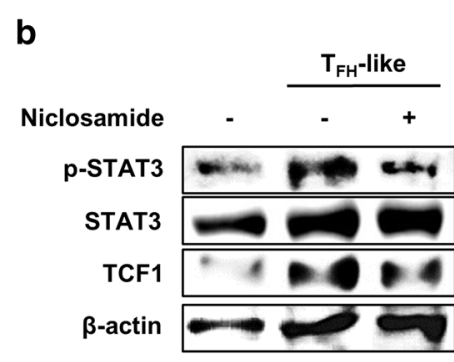

d

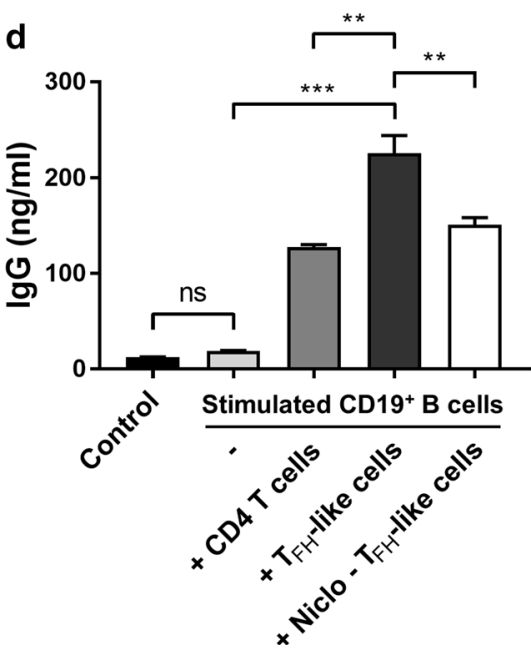

Fig. 4 Niclosamide inhibits $T_{F H}$-like cell differentiation and B cell lgG production in vitro. Naive $\mathrm{CD}^{+}{ }^{+} \mathrm{T}$ cells were purified from the spleens of

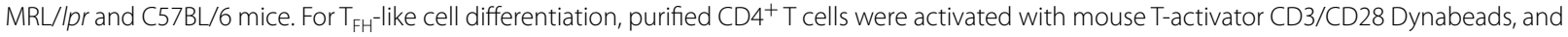
treated with $20 \mathrm{ng} / \mathrm{ml} \mathrm{IL-6,} 20 \mathrm{ng} / \mathrm{ml} \mathrm{IL}-21,10 \mu \mathrm{g} / \mathrm{ml}$ anti-IL-4, $10 \mu \mathrm{g} / \mathrm{ml}$ anti-IFN- $\gamma$, and $20 \mu \mathrm{g} / \mathrm{ml}$ anti-TGF- $\beta$ for 4 days with or without niclosamide. a Left, $\mathrm{T}_{\mathrm{FH}}$-like cells (CXCR5 ${ }^{+} \mathrm{PD}-1^{+}$, gated on $\mathrm{CD}^{+}$) isolated from MRL/lpr mice were analyzed by flow cytometry. Right, the percentage of $\mathrm{FH}^{-}$like cells is shown. $\mathbf{b}$ p-STAT3 and TCF-1 expressions in $\mathrm{T}_{\mathrm{FH}}$-like cells isolated from MRL/lpr mice were analyzed by western blot. c mRNA expression levels of $B C l-6, C X C R 5$, and Blimp-1 in $T_{F H}$-like cells isolated from MRL/Ipr mice were measured by real-time PCR. $\mathbf{d} \mathrm{T}_{\mathrm{FH}}$-like cells and B cells isolated from C57BL/6 mice were co-cultured with or without $\mathrm{T}_{\mathrm{FH}^{-}}$-like cells for 3 days, and then the concentrations of IgG in the supernatants were detected by ELISA. Data shown as mean \pm SD. One-way ANOVA was performed. ${ }^{* *} P<0.01,{ }^{* * *} P<0.001,{ }^{* * *} P<0.0001$, ns: not significant

addition, serum levels of IL-6 and IL-21 were increased following R848 stimulation, while niclosamide treatment prevented these increases (Fig. 5g). R848-induced mice also developed enlarged hypercellular glomeruli, an increase in the mesangial matrix, moderate perivascular mononuclear cell infiltration, glomerular basement membrane thickening, and immune complex deposition. Niclosamide relieved these renal pathological features, decreased histological scores, and inhibited C3 immune complex deposition (Fig. 5h, i). These results suggest that mice topically treated with R848 developed systemic autoimmunity, but this effect was significantly alleviated by niclosamide treatment.

\section{Niclosamide inhibits $\mathrm{CD}^{+}{ }^{+} \mathrm{T}$ cell, $\mathrm{T}_{\mathrm{FH}}$ cell, GC B cell, and PC differentiation in R848-induced mice}

We next sought to determine whether the proportion of $\mathrm{T}$ cell and B cell subsets expanded in response to R848 treatment, and whether this response would be inhibited by niclosamide. $\mathrm{CD}^{+}{ }^{+} \mathrm{T}$ cells, $\mathrm{T}_{\mathrm{FH}}$ cells, $\mathrm{GC}$ B cells, and PCs were significantly increased in the spleens of R848-induced mice (Fig. 6). However, niclosamide significantly decreased the proportion of $\mathrm{CD}^{+} \mathrm{T}$ cells (Fig. 6a, b). The proportion of $\mathrm{T}_{\mathrm{FH}}$ cells was also significantly decreased by niclosamide treatment (Fig. 6c, d). Additionally, when the $\mathrm{T}$ cell subsets analysis was performed, Th1 cells were significantly decreased by niclosamide, while Th17 cells were not affected (Additional file 2: Figure S2). GC B cell proportion in R848induced mice were inhibited by niclosamide (Fig. 6e, f). The proportion of PCs in these mice was significantly reduced by niclosamide treatment (Fig. 6g, h). These data suggest that $\mathrm{R} 848$ enhanced $\mathrm{CD} 4^{+} \mathrm{T}$ cell, $\mathrm{T}_{\mathrm{FH}}$ cell, GC B cell, and PC differentiation, but the expansion of these cells was dramatically prevented by niclosamide. 

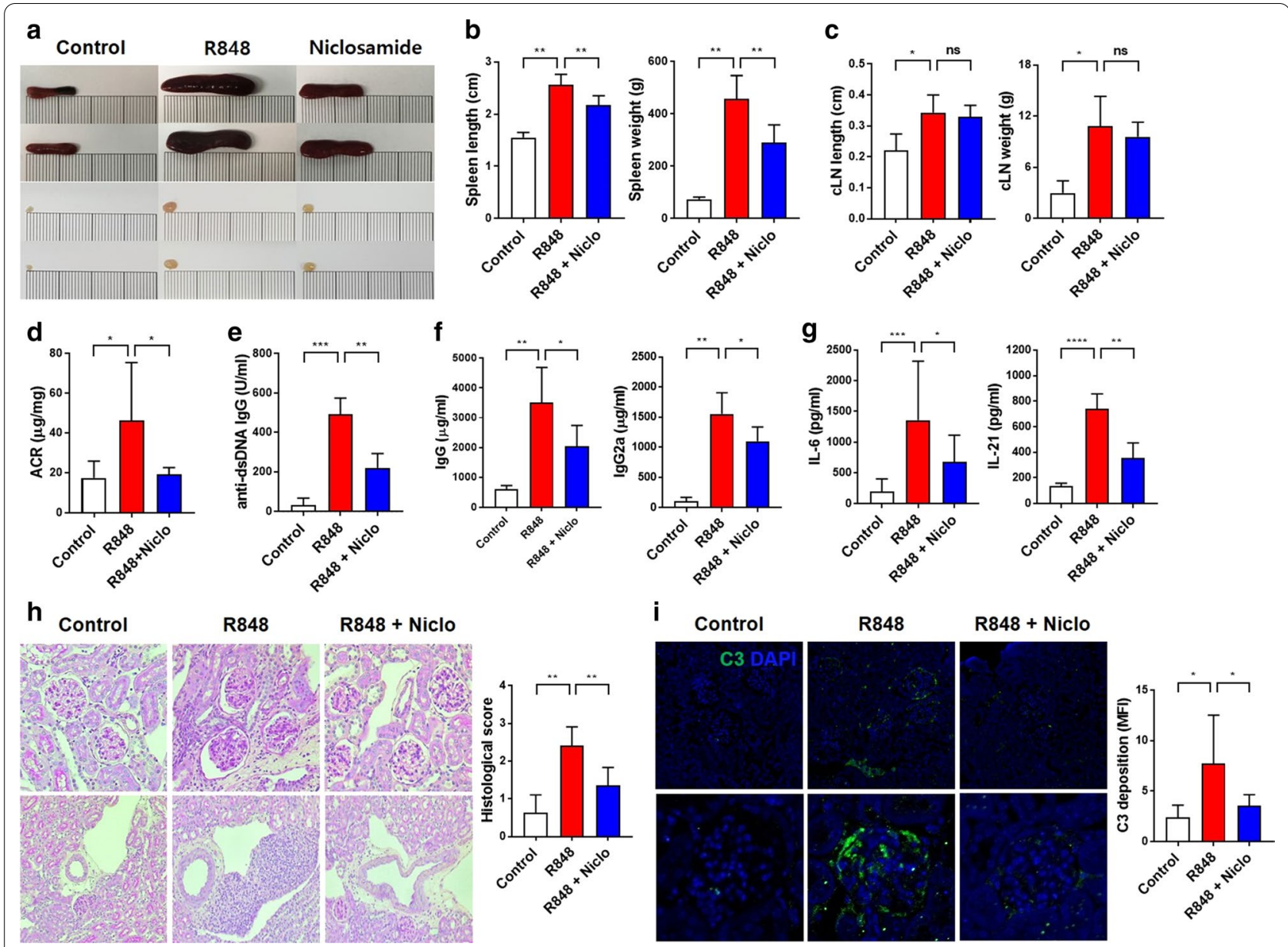

Fig. 5 Niclosamide ameliorates disease aggravation in R848-induced mice. Female 8-week-old C57BL/6 mice were treated with $50 \mu \mathrm{g}$ of the TLR7 agonist R848 or control (acetone) three times weekly and were orally administered $0.5 \%$ methyl cellulose (control, R848, $n=4-6$ ), or 100 mg/kg niclosamide (niclosamide, $n=7$ ) daily until they were 12-week-old. a Representative photographs documenting the enlargement of spleens and CLNs. $\mathbf{b}$ Spleen lengths and weights in each group. $\mathbf{c} C L N$ lengths and weights in each group. $\mathbf{d}$ Urine albumin levels normalized to creatinine. e Serum levels of anti-dsDNA IgG antibody. $\mathbf{f}$ Serum levels of antibody subclasses (IgG, IgG2a). $\mathbf{g}$ Serum levels of IL-6, IL-21. $\mathbf{h}$ Left, representative photomicrographs of PAS-stained sections of kidney. Original magnification $\times 200$ (upper), $\times 100$ (bottom). Right, histological scores. i Left, representative immunofluorescent images of kidney C3 staining. Original magnification $\times 100$ (upper), $\times 400$ (bottom). Right, MFI of C3 deposition. Data shown as mean \pm SD. One-way ANOVA was performed. ${ }^{*} P<0.05,{ }^{* *} P<0.01,{ }^{* *} P<0.001$, ${ }^{* * *} P<0.0001$, ns: not significant

\section{Discussion}

Autoreactive antibody production is one of the hallmarks of SLE and plays a critical pathogenic role in LN [29]. $T_{\mathrm{FH}}$ cells promote autoantibody-producing $B$ cell differentiation in autoimmune diseases. Abnormal expansion of $\mathrm{T}_{\mathrm{FH}}$ cells is a common feature of lupus patients with active disease and is also found in spontaneous and induced models of murine lupus, which suggests that $\mathrm{T}_{\mathrm{FH}}$ cells affect lupus pathogenesis [30, 31]. We hypothesized that STAT3-mediated regulation of $\mathrm{T}_{\mathrm{FH}}$ cells could potentially limit the pathogenicity of the disease. To address this, we used MRL/lpr mice and R848-induced mice. MRL/lpr mice spontaneously develop a severe lupus-like disease that shares several of the immunologic and clinical manifestations of human lupus [32]. Several studies have shown that $\mathrm{T}_{\mathrm{FH}}$ cells are expanded in the spleens of MRL/lpr mice [33, 34]. R848 is an immune-response modifier that activates immune cells through Toll-like receptors (TLRs) 7 and 8 [35]. Epicutaneous application of R848 to $\mathrm{C} 57 \mathrm{BL} / 6$ mice induces the development of lupus-like phenotypes, including mild LN [36]. Activation of plasmacytoid dendritic cells (pDCs) by R848 play a critical role in antigen presentation and $\mathrm{T}$ cell responses [37]. pDCs induce $\mathrm{T}_{\mathrm{FH}}$ cell differentiation through cytokine secretion, such as type I IFN and IL-6 [27, 38]. Although the $\mathrm{T}_{\mathrm{FH}}$ cell differentiation mechanisms differ between the two mouse models, the differentiation 


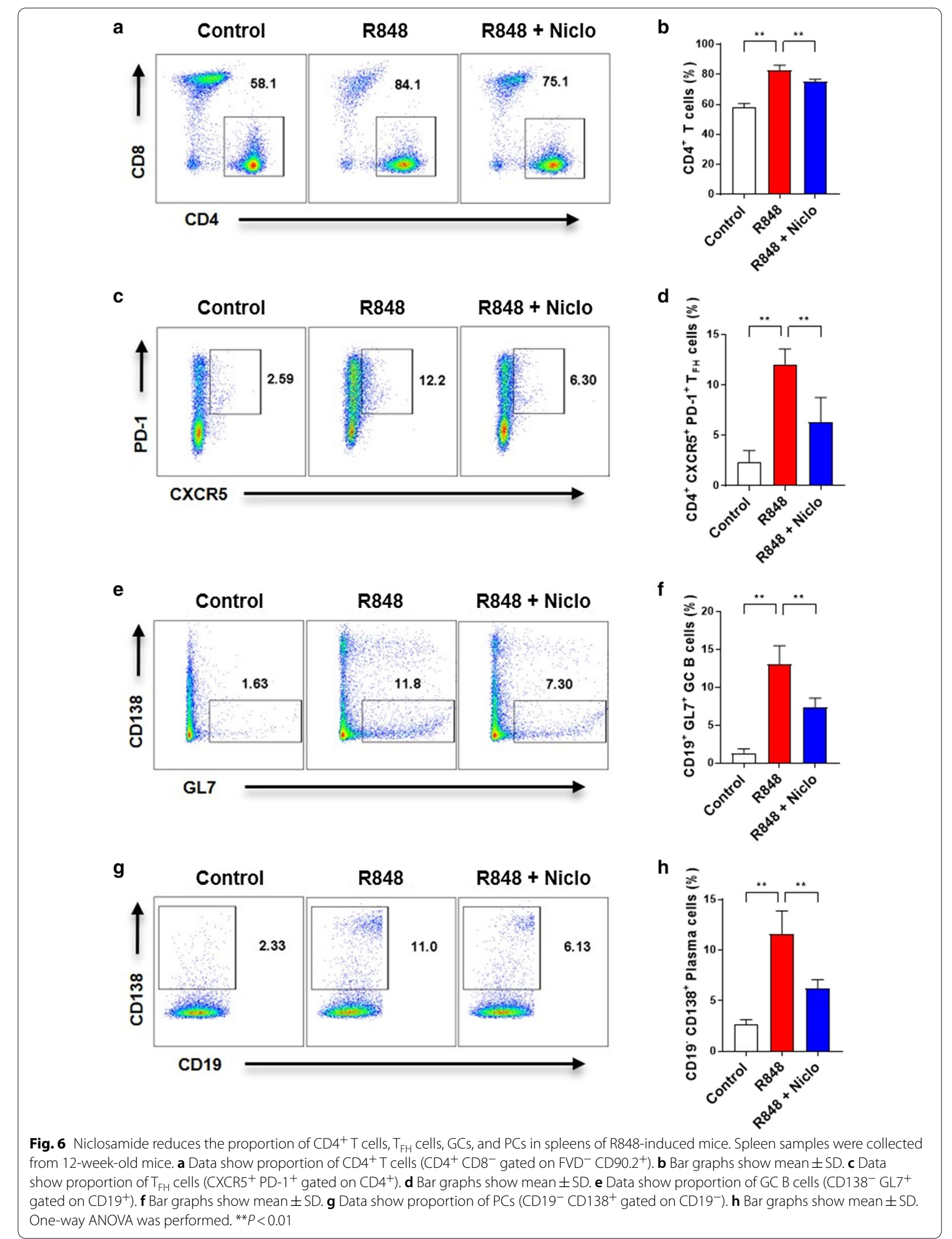


of these cells was significantly inhibited by niclosamide, thereby alleviating the symptoms of lupus.

STAT3 serves multiple biological functions, including playing roles in proliferation, differentiation, and survival through cytokine-mediated signaling in various cells. STAT3 is especially critical for $\mathrm{T}_{\mathrm{FH}}$ and Th17 cell differentiation $[39,40]$. Th17 cells significantly contribute to SLE pathogenesis [41], while inhibition of STAT3 delays the development of lupus pathogenesis by suppressing Th17 cell differentiation [42]. However, we found that niclosamide did not reduce Th17 cell numbers. In addition, DNT cells, which play a crucial pathological role in the development of lupus disease, are expanded in MRL/lpr mice and patients with SLE. In MRL/lpr mice, DNT cells have been found to be the most expanded T cell subset, which lead to splenomegaly and lymphadenopathy [26]. Although we suggested that splenomegaly and lymphadenopathy were not significantly reduced by niclosamide treatment, DNT cell numbers were significantly inhibited. In further studies, we will explore the mechanisms of DNT cell regulation by niclosamide.

Blimp-1 is a well-known antagonist of Bcl-6 that can directly inhibit Bcl-6 expression in T and B cells [43]. Conversely, Bcl-6 can suppress the expression of Blimp-1 [44]. Blimp-1 is a key transcription factor for regulating PC differentiation in B cell lines [45]. Genome-wide association studies have identified multiple SLE-related genes and new susceptibility loci, including Blimp-1 [46]. As mentioned previously, Bcl-6 is strongly upregulated in $\mathrm{T}_{\mathrm{FH}}$ cells [7], while conversely Blimp-1 is the most downregulated transcription factor in $\mathrm{T}_{\mathrm{FH}}$ cells [47]. Bcl-6 and Blimp-1 are mutual master transcription factors regulating $\mathrm{T}_{\mathrm{FH}}$ cell differentiation, and the presence of Bcl-6 coupled with the absence of Blimp-1 is required for $\mathrm{T}_{\mathrm{FH}}$ cell differentiation [9]. In our study, we found that Bcl-6 was significantly decreased in $\mathrm{CD}^{+} \mathrm{T}$ cells by niclosamide administration in MRL/lpr mice, while Blimp-1 was not significantly increased. Further, during $\mathrm{T}_{\mathrm{FH}}$-like cell differentiation in vitro, Bcl-6 was significantly decreased and Blimp-1 was significantly increased by niclosamide treatment.

TCF-1 is crucial for T cell development, as this transcription factor promotes the formation of memory $\mathrm{CD}^{+} \mathrm{T}$ cells, Th2 cells, and $\mathrm{T}_{\mathrm{FH}}$ cells. TCF- 1 is highly expressed and regulates the early stages process of $\mathrm{T}_{\mathrm{FH}}$ cell differentiation [13]. $\mathrm{Xu}$ et al. reported that TCF-1 functions as an upstream regulator of the Bcl-6 / Blimp-1 axis, critical for $\mathrm{T}_{\mathrm{FH}}$ differentiation [48]. Certain cytokines secreted by immune cells in the disease milieu, such as IL-6 and IL-21 $[49,50]$, might induce the immediate upregulation of TCF-1 expression through STAT3 signaling. We found that niclosamide decreased serum levels of IL-6 and IL-21. Niclosamide also inhibited
TCF-1 expression in the spleens of MRL/lpr mice and in $\mathrm{T}_{\mathrm{FH}}$-like cells.

Niclosamide induce cell cycle arrest, growth inhibition and apoptosis in cancer cells by targeting multiple signaling pathways such as, Wnt/ $\beta$-catenin, STAT3, mTOR, Notch signaling pathways and mitochondria metabolic pathways [51]. Han et al. demonstrated that niclosamide ethanolamine alleviated lupus nephritis in MRL/lpr mice, and regulated mitochondrial biogenesis and energy metabolism in the kidney [52]. An important feature of mitochondria is it can regulate activation, differentiation, and survival of immune cells such as, $\mathrm{T}$ cell, B cell, macrophage, DC in autoimmune disease [53]. However, the authors work focused primarily on the kidney and did not extensively address potential immunological mechanisms. In our study, it is necessary to further study the mechanism by which niclosamide induced mitochondria function change affects $\mathrm{T}_{\mathrm{FH}}$ cells.

\section{Conclusion}

The present study showed that niclosamide significantly alleviated SLE-like characteristics in MRL/lpr and R848induced mice models. Our data also demonstrated the regulatory function of niclosamide on $\mathrm{T}_{\mathrm{FH}}$ cells in vivo and in vitro. Targeting STAT3 signaling using niclosamide could be an effective therapy for treating LN.

\section{Supplementary Information}

The online version contains supplementary material available at https://doi. org/10.1186/s12967-021-02760-2.

Additional file 1. Additional figures

\section{Abbreviations}

ACR: Albumin to creatinine ratio; BATF: Basic leucine zipper transcriptional factor ATF-like; Bcl-6: B cell lymphoma 6; Blimp-1: B lymphocyte-induced maturation protein 1; CLN: Cervical lymph node; DAPI: 4',6-Diamidino-2-phenylindole; DNT: Double-negative T; FVD: Fixable viability dye; dsDNA: Double-stranded DNA; GC: Germinal center; IRF4: Interferon regulatory factor 4; MC: Methylcellulose; NSAIDs: Non-steroidal anti-inflammatory drugs; PAS: Periodic acidSchiff; PB: Peripheral blood; PCs: Plasma cells; pDC: Plasmacytoid dendritic cells; PMA: Phorbol 12-myristate 13-acetate; SDS-PAGE: Sodium dodecyl sulfate polyacrylamide gel electrophoresis; SLE: Systemic lupus erythematosus; STAT3: Signal transducer and activator of transcription 3; TCF-1: T cell factor 1; TFH: Follicular helper T; TLR7: Toll-like receptor 7; Treg: Regulatory T.

\section{Acknowledgements \\ None.}

Authors' contributions

Study conception and design were performed by SGJ, JSL, SKK, SHP, data acquisition was performed by SGJ, JSL, SMH, YSS, MJK and data analysis and interpretation were performed by SGJ, JSL, SKK, MLC, SHP. All authors read and approved the final manuscript.

\section{Funding}

This research was supported by a grant of the Korea Health Technology R\&D Project through the Korea Health Industry Development Institute (KHIDI), funded by the Ministry of Health \& Welfare, Republic of Korea (HI20C1496), 
Basic Science Research Program through the National Research Foundation of Korea (NRF) funded by the Ministry of Education (2020R111A1A01074126).

\section{Availability of data and materials}

All data are available in the manuscript or upon request to the authors.

\section{Ethics approval and consent to participate}

All procedure of animal research were provided in accordance with the Laboratory Animals Welfare Act, the Guide for the Care and Use of Laboratory Animals and the Guidelines and Policies for Rodent experiment provided by the IACUC(Institutional Animal Care and Use Committee) in school of medicine, The Catholic University of Korea. (Approval numbers: CUMS-2018-034102 and 2018-0236-02).

\section{Consent for publication}

Not applicable.

\section{Competing interests}

The authors declare that they have no competing interest.

\section{Author details}

${ }^{1}$ The Rheumatism Research Center, Catholic Research Institute of Medical Science, College of Medicine, The Catholic University of Korea, Seoul, Republic of Korea. ${ }^{2}$ Division of Rheumatology, Department of Internal Medicine, Seoul St. Mary's Hospital, College of Medicine, The Catholic University of Korea, Seoul, Republic of Korea.

Received: 12 November 2020 Accepted: 19 February 2021 Published online: 25 February 2021

\section{References}

1. Tsokos GC. Systemic lupus erythematosus. N Engl J Med. 2011:365:2110-21.

2. Furumoto Y, Smith CK, Blanco L, et al. Tofacitinib ameliorates murine lupus and its associated vascular dysfunction. Arthritis Rheumatol. 2017;69:148-60.

3. Vlachou K, Mintzas K, Glymenaki M, et al. Elimination of granulocytic myeloid-derived suppressor cells in lupus-prone mice linked to reactive oxygen species-dependent extracellular trap formation. Arthritis Rheumatol. 2016;68:449-61.

4. Xu B, Wang S, Zhou M, et al. The ratio of circulating follicular Thelper cell to follicular T regulatory cell is correlated with disease activity in systemic lupus erythematosus. Clin Immunol. 2017;183:46-53.

5. Crotty S. Follicular helper CD4T cells (TFH). Annu Rev Immunol. 2011;29:621-63.

6. Breitfeld D, Ohl L, Kremmer E, et al. Follicular B helper T cells express CXC chemokine receptor 5 , localize to $B$ cell follicles, and support immunoglobulin production. J Exp Med. 2000;192:1545-52.

7. Yu D, Rao S, Tsai LM, et al. The transcriptional repressor BCl-6 directs T follicular helper cell lineage commitment. Immunity. 2009;31:457-68.

8. Tangye SG, Ma CS, Brink R, Deenick EK. The good, the bad and the ugly - TFH cells in human health and disease. Nat Rev Immunol. 2013;13:412-26.

9. Johnston RJ, Poholek AC, DiToro D, et al. Bcl6 and Blimp-1 are reciprocal and antagonistic regulators of $T$ follicular helper cell differentiation. Science. 2009;325:1006-10.

10. Nurieva RI, Podd A, Chen Y, et al. STAT5 protein negatively regulates T follicular helper (Tfh) cell generation and function. J Biol Chem. 2012;287:11234-9.

11. Gensous N, Schmitt N, Richez C, Ueno H, Blanco P.T follicular helper cells, interleukin-21 and systemic lupus erythematosus. Rheumatology (Oxford). 2017;56:516-23.

12. Hillmer EJ, Zhang H, Li HS, Watowich SS. STAT3 signaling in immunity. Cytokine Growth Factor Rev. 2016;31:1-15.

13. Chen Y, Yu D. TCF-1 at the Tfh and Th1 Divergence. Trends Immunol. 2015;36:758-60

14. Wu T, Shin HM, Moseman EA, et al. TCF1 is required for the T follicular helper cell response to viral infection. Cell Rep. 2015;12:2099-110.
15. Hodge DR, Hurt EM, Farrar WL. The role of IL-6 and STAT3 in inflammation and cancer. Eur J Cancer. 2005;41:2502-12.

16. Ding $C$, Chen $X$, Dascani $P$, et al. STAT3 Signaling in B cells is critical for germinal center maintenance and contributes to the pathogenesis of murine models of lupus. J Immunol. 2016;196:4477-86.

17. Edwards $L J$, Mizui M, Kyttaris V. Signal transducer and activator of transcription (STAT) 3 inhibition delays the onset of lupus nephritis in MRL/Ipr mice. Clin Immunol. 2015;158:221-30.

18. Dang WZ, Li H, Jiang B, et al. Therapeutic effects of artesunate on lupusprone MRL/Ipr mice are dependent on $\mathrm{T}$ follicular helper cell differentiation and activation of JAK2-STAT3 signaling pathway. Phytomedicine. 2019;62:152965.

19. Chen W, Mook RA Jr, Premont RT, et al. Niclosamide: Beyond an antihelminthic drug. Cell Signal. 2018;41:89-96.

20. Sack U, Walther W, Scudiero D, et al. Novel effect of antihelminthic on S100A4-mediated metastatic progression in colon cancer. J Natl Cancer Inst. 2011;103:1018-36.

21. Yo YT, Lin YW, Wang YC, et al. Growth inhibition of ovarian tumor-initiating cells by niclosamide. Mol Cancer Ther. 2012;11:1703-12.

22. Thatikonda S, Pooladanda V, Godugu C. Repurposing an old drug for new use: niclosamide in psoriasis-like skin inflammation. J Cell Physiol. 2020;235:5270-83.

23. Chang X, Zhen X, Liu J, et al. The antihelmenthic phosphate niclosamide impedes renal fibrosis by inhibiting homeodomain-interacting protein kinase 2 expression. Kidney Int. 2017;92:612-24.

24. Ren $X$, Duan $L, H e Q$, et al. Identification of Niclosamide as a New SmallMolecule Inhibitor of the STAT3 Signaling Pathway. ACS Med Chem Lett. 2010;1:454-9.

25. Kim YY, Park KT, Jang SY, et al. HM71224, a selective Bruton's tyrosine kinase inhibitor, attenuates the development of murine lupus. Arthritis Res Ther. 2017:19:211.

26. Wang J, Mizui M, Zeng LF, et al. Inhibition of SHP2 ameliorates the pathogenesis of systemic lupus erythematosus. J Clin Invest. 2016;126:2077-92.

27. Ballesteros-Tato A, Randall TD. Priming of T follicular helper cells by dendritic cells. Immunol Cell Biol. 2014;92:22-7.

28. He L, Gu W, Wang M, et al. Extracellular matrix protein 1 promotes follicular helper T cell differentiation and antibody production. Proc Natl Acad Sci U S A. 2018;115:8621-6.

29. Yu D, Vinuesa CG. Multiple checkpoints keep follicular helper T cells under control to prevent autoimmunity. Cell Mol Immunol. 2010;7:198-203.

30. Craft JE. Follicular helper T cells in immunity and systemic autoimmunity. Nat Rev Rheumatol. 2012;8:337-47.

31. Faliti CE, Gualtierotti R, Rottoli E, et al. P2X7 receptor restrains pathogenic Tfh cell generation in systemic lupus erythematosus. J Exp Med. 2019;216:317-36

32. Liu J, Karypis G, Hippen KL, et al. Genomic view of systemic autoimmunity in MRLIpr mice. Genes Immun. 2006;7:156-68.

33. Yang $X$, Yang J, Chu Y, et al. T follicular helper cells mediate expansion of regulatory B cells via IL-21 in Lupus-prone MRL/Ipr mice. PLoS ONE. 2013;8:e62855.

34. Yang J, Yang $X$, Yang J, Li M. Baicalin ameliorates lupus autoimmunity by inhibiting differentiation of Tfh cells and inducing expansion of Tfr cells. Cell Death Dis. 2019:10:140.

35. Lee J, Chuang TH, Redecke V, et al. Molecular basis for the immunostimulatory activity of guanine nucleoside analogs: activation of Toll-like receptor 7. Proc Natl Acad Sci USA. 2003;100:6646-51.

36. Yokogawa M, Takaishi M, Nakajima K, et al. Epicutaneous application of toll-like receptor 7 agonists leads to systemic autoimmunity in wild-type mice: a new model of systemic Lupus erythematosus. Arthritis Rheumatol. 2014;66:694-706.

37. Rajagopal D, Paturel C, Morel Y, Uematsu S, Akira S, Diebold SS. Plasmacytoid dendritic cell-derived type I interferon is crucial for the adjuvant activity of Toll-like receptor 7 agonists. Blood. 2010;115:1949-57.

38. Blanco P, Ueno H, Schmitt N. T follicular helper (Tfh) cells in lupus: activation and involvement in SLE pathogenesis. Eur J Immunol. 2016:46:281-90.

39. Egwuagu CE. STAT3 in CD4+ Thelper cell differentiation and inflammatory diseases. Cytokine. 2009;47:149-56.

40. Ray JP, Marshall HD, Laidlaw BJ, Staron MM, Kaech SM, Craft J. Transcription factor STAT3 and type I interferons are corepressive insulators 
for differentiation of follicular helper and Thelper 1 cells. Immunity. 2014:40:367-77.

41. Kono M, Yoshida N, Maeda K, Tsokos GC. Transcriptional factor ICER promotes glutaminolysis and the generation of Th17 cells. Proc Natl Acad Sci U S A. 2018;115:2478-83.

42. Kluger MA, Melderis S, Nosko A, et al. Treg17 cells are programmed by Stat 3 to suppress Th17 responses in systemic lupus. Kidney Int 2016;89:158-66.

43. Martins G, Calame K. Regulation and functions of Blimp-1 in T and B lymphocytes. Annu Rev Immunol. 2008;26:133-69.

44. Shaffer AL, Yu X, He Y, Boldrick J, Chan EP, Staudt LM. BCL-6 represses genes that function in lymphocyte differentiation, inflammation, and cell cycle control. Immunity. 2000;13:199-212.

45. Shapiro-Shelef M, Lin Kl, Savitsky D, Liao J, Calame K. Blimp-1 is required for maintenance of long-lived plasma cells in the bone marrow. J Exp Med. 2005;202:1471-6.

46. Gateva V, Sandling JK, Hom G, et al. A large-scale replication study identifies TNIP1, PRDM1, JAZF1, UHRF1BP1 and IL10 as risk loci for systemic lupus erythematosus. Nat Genet. 2009;41:1228-33.

47. Fazilleau N, McHeyzer-Williams $\sqcup$, Rosen $\mathrm{H}$, McHeyzer-Williams MG. The function of follicular helper T cells is regulated by the strength of T cell antigen receptor binding. Nat Immunol. 2009;10:375-84.

48. Xu L, Cao Y, Xie Z, et al. The transcription factor TCF-1 initiates the differentiation of T(FH) cells during acute viral infection. Nat Immunol. 2015;16:991-9.
49. Cronin JG, Kanamarlapudi V, Thornton CA, Sheldon IM. Signal transducer and activator of transcription-3 licenses Toll-like receptor 4-dependent interleukin (IL)-6 and IL-8 production via IL-6 receptor-positive feedback in endometrial cells. Mucosal Immunol. 2016;9:1125-36.

50. Deng XM, Yan SX, Wei W. IL-21 acts as a promising therapeutic target in systemic lupus erythematosus by regulating plasma cell differentiation. Cell Mol Immunol. 2015;12:31-9.

51. LiY, Li PK, Roberts MJ, et al. Multi-targeted therapy of cancer by niclosamide: a new application for an old drug. Cancer Lett. 2014:349:8-14

52. Han P, Weng W, Chen Y, et al. Niclosamide ethanolamine attenuates systemic lupus erythematosus and lupus nephritis in MRL/lpr mice. Am J Transl Res. 2020;12:5015-31.

53. Angajala A, Lim S, Phillips JB, et al. Diverse Roles of Mitochondria in immune responses: novel insights into immuno-metabolism. Front Immunol. 2018;9:1605.

\section{Publisher's Note}

Springer Nature remains neutral with regard to jurisdictional claims in published maps and institutional affiliations.
Ready to submit your research? Choose BMC and benefit from:

- fast, convenient online submission

- thorough peer review by experienced researchers in your field

- rapid publication on acceptance

- support for research data, including large and complex data types

- gold Open Access which fosters wider collaboration and increased citations

- maximum visibility for your research: over $100 \mathrm{M}$ website views per year

At BMC, research is always in progress.

Learn more biomedcentral.com/submissions 